\title{
Author Correction: Integrating oncolytic viruses in combination cancer immunotherapy
}

Praveen K. Bommareddy, Megha Shettigar and Howard L. Kaufman

Nature Reviews Immunology (2018) https://doi.org/10. 1038/s41577-018-0014-6

Published online 09 May 2018

In the initially published version of this article online in advance of print, a reference (Ajina, A. \& Maher, J. Prospects for combined use of oncolytic viruses and CAR T-cells. J. Immunother. Cancer 5, 90 (2017)) was omitted in error from the following sentence: "The ability of oncolytic viruses to increase the expression of MHC class I molecules by cancer cells is also predicted to enhance ACT with TILs or TCR-engineered and chimeric antigen receptor (CAR) T cells that target tumour-specific antigens". This has been corrected in the HTML and PDF versions of the manuscript.

https://doi.org/10.1038/s41577-018-0031-5 I Published online 21 June 2018

\section{Publisher Correction: To respond or not to respond a personal perspective of intestinal tolerance}

Allan Mcl. Mowat

Nature Reviews Immunology (2018) https://www.nature.com/articles/s41577-018-0002-x Published online 28 February 2018

In the originally published article, several references in the Timeline figure were missing or incorrect. This mistake has now been corrected and the publisher apologizes for this error.

https://doi.org/10.1038/s41577-018-0033-3 I Published online 22 June 2018 